\title{
Burmese Migrant Workers: Dimensions of Cultural Adaptation and an Assimilation Model for Economic and Social Development in the Central Coastal Region of Thailand
}

\author{
Kamonchat Pathumsri ${ }^{1}$, Boonsom Yodmalee ${ }^{1} \&$ Kosit Phaengsoi $^{1}$ \\ ${ }^{1}$ The Faculty of Cultural Science, Mahasarakham University, Khamriang Sub-District, Kantarawichai District, \\ Maha Sarakham Province, Thailand \\ Correspondence: Kamonchat Pathumsri, The Faculty of Cultural Science, Mahasarakham University, Khamriang \\ Sub-District, Kantarawichai District, Maha Sarakham Province 44150, Thailand. E-mail: \\ kpathumsri152@gmail.com
}

Received: July 7, 2014 Accepted: July 15, 2014 Online Published: September 22, 2014

doi:10.5539/ach.v7n1p35

URL: http://dx.doi.org/10.5539/ach.v7n1p35

\begin{abstract}
This research is aimed at studying the background of Burmese migrant labor, the current state and problems with Burmese migrant labor and the dimensions of cultural adaptation and an assimilation model for economic and social development of Burmese migrant labor in the Central Coastal Region of Thailand. This is a qualitative study carried out between November 2012 and November 2013 that incorporates document study and field research. The research area was purposively selected as Samut Sakhon, Samut Prakan and Samut Songkhram Provinces. The research sample was also purposively selected and comprised of 150 individuals, divided into three groups: key informants $(n=21)$, casual informants $(n=69)$ and general informants $(n=60)$. Tools used for data collection were observation, interview and focus group discussion. Data was validated using a triangulation technique. The result of the investigation is a development model in five sections: cost of labor, work conditions, job security, career progression and work sanitation and safety.
\end{abstract}

Keywords: Burmese migrant labor, cultural adaptation, cultural dimensions, social development, economy

\section{Introduction}

In recent years, the strength of the Western economy has influenced the Eastern economy, which has grown as a result and now looks like being an important part of the global economic situation for the foreseeable future (Media, 2012). Globalization has affected the economy in such a way that borders and governments are much more fluid when it comes to labor and finances (Achawanichagul, 2002). Thailand is no exception (Chantavanit, 2001). There are two types of causes for labor migration to Thailand from neighboring countries, which are push factors and pull factors. Pull factors are primarily related to the strength of the Thai economy in relation to surrounding countries. Push factors are generally problems in the home country of the immigrants, such as economic or political problems. Most working immigrants in Thailand come from Laos, Myanmar and Cambodia. The GNP of Thailand is six times that of Myanmar, seven times that of Laos and twelve times that of Cambodia (Huget \& Punpuing, 2005). Additionally, the population expansion ratio in Thailand has decreased. Almost all Burmese laborers have immigrated to Thailand due to political conflict in Myanmar and population over-control. These affected Burmese life security and safety, making them were willing to move by both legal and illegal means to find jobs in Thailand where better economic growth and lifestyle were on offer. There was also a lack of labor in Thailand because Thai people didn't want to be employed for the low wages available. Those Burmese workers responded to the needs of the economy and helped many entrepreneurs spend much less on labor. The government defense measurements for illegal immigrants were regulated in BE 2555 (2012) and stated that entrepreneurs must register their foreign laborers as legal immigrants (Office of foreign worker administration, 2011). The Central Coastal Region of Thailand is one area where many Burmese workers would like to come and be employed because of the appropriate location within industrial cities where the economy, society, politics and culture are quite similar to the Bangkok metropolis. There are socio-economic problems with Burmese laborers in Thailand. Not only do Burmese laborers compete with Thai workers in the employment market but also cause problems of Thai national security, health and safety, as seen in current criminal news. For more than a century, Thailand has tried to manage these problems, which seem to be out of control. This has resulted in decreasing Thai labor productivity and a chronic lack of labor force. In BE 2558 
(2015), Thailand will enter as a member of the ASEAN Economic Community (AEC) and the international workflow will increase. The Burmese are prepared to open their borders and welcome the trend of globalized capitalism making their economy more attractive to international entrepreneurs by granting an eight-year tax exemption. This will affect Thailand because Myanmar has locations with large reserves of natural resources, water and electric plants, many Burmese are good at speaking English and the country is geographically connected to India and important maritime trade routes. The danger is that Burmese workers will see more opportunity in their homeland and return, causing employment shortages in Thailand (Wiwattanangan, 2012). Almost all Burmese laborers immigrate to Thailand because of push and pull factors giving them a better lifestyle. Unfortunately, they may be exploited by their employer and officers who attempt to find benefit in their situation. Human rights violations and oppression are destroying Burmese labor security and safety (Sibpapart, 2009). Nevertheless, Burmese laborers feel inclined to work for a better life and family survival. The researchers recognized that foreign employment must be improved to benefit both foreign workers and Thailand and maintain their relations. The researchers thus conducted this investigation of Burmese migrant workers: Dimensions of cultural adaptation and an assimilation model for economic and social development in the Central Coastal Region of Thailand.

\section{Research Methodology}

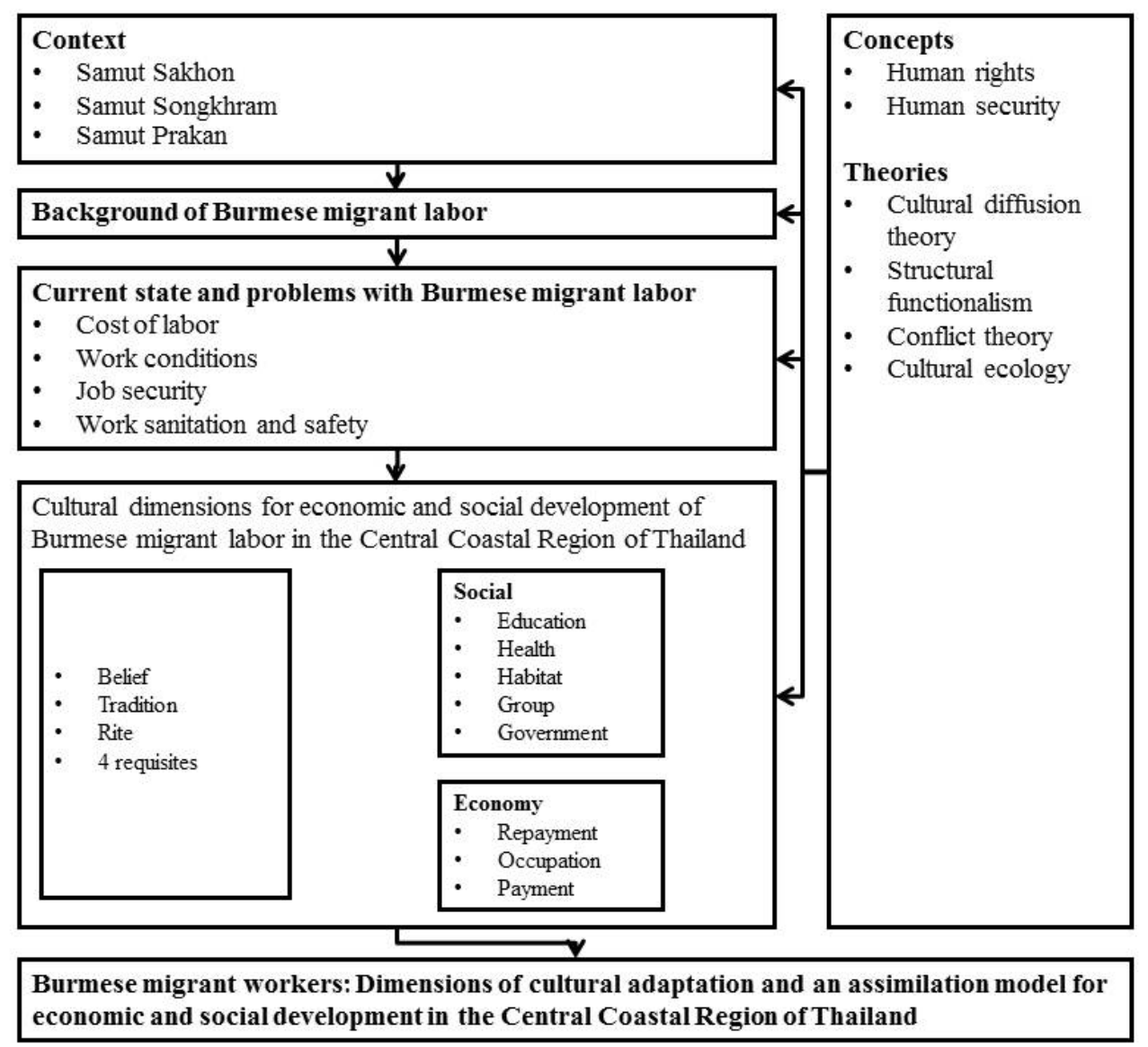

Figure 1. Research framework

This is a qualitative study carried out between November 2012 and November 2013 that incorporates document study and field research. The research area was purposively selected as Samut Sakhon, Samut Prakan and Samut Songkhram Provinces. These three provinces were chosen because they have a high number of Burmese workers in local industry. The research sample was also purposively selected and comprised of 150 individuals, divided into three groups: key informants $(n=21)$, casual informants $(n=69)$ and general informants $(n=60)$. Tools used for data collection were participant and non-participant observation, structured and non-structured interview and focus group discussion. Data was validated using a triangulation technique. Analysis was conducted by typological analysis and analytic induction. The results are here presented as a descriptive analysis. 


\section{Results}

\subsection{History of Burmese Immigrant Laborers Working in the Central Coastal Region of Thailand}

Initially, Burmese workers were illegally smuggled through Thailand and worked as crews on fishing boats or as laborers. After Typhoon Gay hit Thailand and killed many Thai fishing crews, mostly Thai workers from the North-eastern region, in BE 2532 (1989), Thai workers were frightened away, causing a lack of workers in the industry. Employers had to find workers from other regions instead and started to employ Burmese workers due to their patience and willingness to work hard for low payment. Later, other entrepreneurs such as palm, coffee or rubber plantation owners in Southern Thailand became interested in hiring more laborers from Myanmar. Later, Burmese workers immigrated more to Central Thailand to work in various businesses: sugar cane harvesting, rice mill, potatoes and other agricultural industries. Burmese immigrants moved to and worked in the Central Coastal Region of Thailand: Samut Sakhon, Samut Songkhram, and Samut Prakarn provinces. In BE 2539 (1995) the Thai government permitted foreign immigrants (Burmese, Lao and Cambodian) to be employed in some areas of Thailand. This made Thailand change from a labor export country to a country welcoming to foreign workers. There are three ways Burmese immigrants move into Thailand: 1) Immigrate under the foreign workers employment memorandum of understanding (MOU), mostly found in large and well systemized enterprises. They immigrate through the requirements that the owners offer to Thai governments. Burmese workers will be taken from Myanmar by employment agencies; 2) Immigrate with nationality approved under the council of ministers resolution. These laborers can be found in medium-sized enterprises and mostly come to Thailand as travelers with 1-3 months traveling visas, before asking for annual working licenses given by the ministry of labor and social welfare; and 3) Immigrate Illegally, as seen in small and medium enterprises. These enterprises do not usually have well systemized organizations. Burmese workers in this group have moved to Thailand through border stations or ferries landing along the Thailand-Myanmar border area used for goods exchange. Another instance is as a traveler with 1-3 months traveling who neither asks for an annual working license nor gets their nationality approved under the council of ministers resolution, having lived in Thailand for more than 10 years. There are two immigration types used by Burmese immigrants: 1) agencies and 2) self immigration. The Central Coastal Region of Thailand has both legal and illegal foreign laborers but it is difficult to find the actual amount, so the government has permitted and expanded the time limit for nationality approval for Burmese, Lao and Cambodian laborers immigrating illegally in order to allow them to register for a legal working license.

\subsection{Conditions and Problems of Burmese Immigrant Laborers Working in the Central Coastal Region of Thailand}

The researchers have divided the conditions and problems of Burmese immigrant laborers working in the Central Coastal Region of Thailand as follows:

\subsubsection{Cost of labor}

All foreign labor wages and welfare are provided according to the law of labor employment and protection. Legal foreign laborers will receive wages and social security welfare as Thai laborers, a minimum of 300 baht daily wage and overtime duty of 56 baht per hour.

\subsubsection{Work Conditions}

Burmese laborers work up to 8 hours a day, with 1 hour rest after 5 hours work. This working time schedule depends on each factory. Almost all large factories in Samut Sakhon have divided their working time into 2 periods: around 7-8AM to 5-7PM (11AM or 12PM break) and 7PM to 7AM (11PM break). According to interviews with Burmese laborers, they are willing to work overtime duty for higher wages no matter how long they have to work. They attempt to keep that wage to send back home to Myanmar.

\subsubsection{Job Security}

Work security is very high in Samut Sakhon Province due to demand. Enterprises never contemplate firing laborers. However, Burmese laborers usually quit themselves when their friends or family members working in different factories offer them better work. This communication causes job comparisons, making Burmese laborers change their job to for better positions.

\subsubsection{Career Progression}

Burmese laborers who have worked in Thailand for over 5-10 years can speak Thai and are promoted to positions as head of a labor team, which means their wage will be increased by $20-50$ baht per hour. If some 
Burmese laborers are also able to speak English, they will be promoted as officers to communicate with other foreigners.

\subsubsection{Work Sanitation and Safety}

These two conditions will be looked after according to the law of labor hospitalization rights and health welfare, which Burmese laborers could receive either from social security welfare or health insurance welfare.

\subsection{A Burmese Immigrant Labor Cultural Adaptation and Assimilation Model for Economic and Social Development in the Central Coastal Region of Thailand}

The researchers created a Burmese immigrant labor cultural adaptation and assimilation model for economic and social development in the Central Coastal Region of Thailand with five sections: cost of labor, work conditions, job security, career progression and work sanitation and safety.

\subsubsection{Cost of Labor}

Almost all Burmese immigrant laborers working in Thailand aim to get as much income as they can and save money to send back home for family to raise their quality of life. To work in a foreign country happily, Burmese immigrant laborers have to act in accordance with the principles of Thai society. The education of many Burmese immigrants is quite low; some of them have never studied and they hold strong beliefs in religious and traditional health care, preferring to return to Myanmar and ask Khmer monks or fortune tellers to cure them when they get sick rather than going to hospital in Thailand. Nevertheless, some Burmese immigrant laborers in Thailand are trying to adjust themselves according to Thai lifestyle for safety and survival. For example, Burmese men wear trousers instead of sarongs to avoid standing out to the police. Some Burmese immigrants who have a high enough level of education are treated by doctors. At the same time, Thai society is trying to provide many facilities and give them more recognition due to the similarities between both nationalities. This represents easy adaptation for Burmese immigrant laborers.

\subsubsection{Work Conditions}

Burmese immigrant labor work conditions in Thailand are improving and becoming more stable. According to the traditional dimensions of cultural assimilation, it was found that Burmese laborers respect Buddhism like Thai people. Thus the traditions and cultures of both countries are similar, for example Songkran festival, ordination ceremonies and marriage ceremonies. All previous traditions are strongly related to Buddhism.

\subsubsection{Job Security}

According to the job security dimension of cultural assimilation, it was found that every Burmese performance and play, such as Myanmar traditional dramatic performances or Burmese traditional dance in various occasions can be arranged with the permission of provincial governors, considering appropriation to public security and the risk of civil commotion.

\subsubsection{Career Progression}

Burmese immigrant laborers who work in Thailand and have developed their experience and expertise are promoted to better positions. This means that they can self-adapt in harmony with the customs and beliefs of both Thailand and Myanmar.

\subsubsection{Work Sanitation and Safety}

In the work sanitation and safety dimension of cultural assimilation, it was found that there are four basic human necessities (food, clothes, shelter and medicine). 1) Both Thai and Burmese people mainly eat rice at each meal and additional comfortable shipments and transportation between these two countries mean that Burmese immigrant laborers' eating habits in Thailand can be easily adjusted. The food consumption culture of some Burmese immigrant laborers requires them to eat with their fingers but recently they have adjusted themselves by using utensils such as spoons or chopsticks in public places. Another untidy habit that all new Burmese immigrants (both genders) usually have is chewing and spitting out betel nut mixed in the work place and public areas. This behavior will decrease about 1 month after working. 2) Burmese immigrant laborers wear clothing depending on the regulations of each enterprise. At the same time, clothes worn at home are similar to Burmese national costume, including a shirt and sarong. In public places, such a department store, they will dress in accordance with Thai fashion. 3) Some Burmese immigrant laborers live in rented rooms with room-maids or family members but some Burmese laborers stay in flats or terrace houses where the owner waives the rent fee, although they must cover the cost of utilities. Burmese immigrant habitation in Thailand is quite overcrowded and insanitary because almost all Burmese laborers have low levels of education and public consciousness. A lot of trash and garbage is scattered in and around their living areas. In addition, Burmese immigrant laborers have 
poor levels of road discipline and accidents often occur. 4) Some Burmese immigrant laborers use folk herbal medicines but most usually see doctors at both government and private hospitals.

\section{Conclusion}

The researchers found that the Burmese immigrant labor cultural adaptation and assimilation model for economic and social development in the Central Coastal Region of Thailand consists of five sections: cost of labor, work conditions, job security, career progression and work sanitation and safety. This model can explain the cultural behavior of Burmese immigrant laborers related to the working state in Thailand.

\section{Discussion}

Immigration of Burmese laborers to Thailand began in the late $20^{\text {th }}$ century when the Thai economy was booming. This Burmese group was an important factor in the Thai manufacturing process. Mr. Yod Santisombat (1994) said that culture is human thinking and behavior which is permanently carried with people whereever they go or live. Thus, cultural diffusion may depend on geography, transportation, economy and social factors. The researchers found that in this case, the main factor of Burmese labor immigration to the Central Coastal Region of Thailand is economic growth in Thailand and comfortable transportation. Triphop Tungmankhong (2009) studied Burmese immigrant labor in Samut Sakhon province and found that important push factors causing Burmese immigrants to move to Thailand are internal wars, unemployment and poverty.

This study corresponds to the conflict theory of Karl Marx. Marx explained that the conflict theory is a part of a practical argument model between class confliction and social change, consisting of three principles: 1) for economic organization, owners determine principles such as structural-functional class, institute collocation, social value systemization and religious beliefs in the social group; 2 ) conflict in any society can originate from groups or classifications; and 3) conflict is a bipolar phenomenon concerning the exploited class and the ruling class. Kritsana Awanitchakul at al. (1999) studied the effect of foreign immigrant labor employment on Thailand security. They found that there are both positive and negative effects from Thailand hiring foreign immigrant labor: The positive effects are decreased worker insufficiency and cost of manufacturing; the negative effect is work market competition between Thai laborers and foreign immigrant laborers.

According to the Burmese immigrant labor cultural adaptation and assimilation model for economic and social development in the Central Coastal Region of Thailand, Burmese immigrant labors in Thailand are trying to adjust themselves according to Thai lifestyle for safety and survival. At the same time, Thai society is trying to provide many facilities and give them more representation due to the similarities between both nationalities. This ensures that adaptation is not too hard for Burmese immigrant labors. This corresponds to the concept of cultural ecology, 'the study of the processes by which a society adapts to its environment.'

\section{Suggestions}

\subsection{Suggestions for the Practical Implementation of the Result}

- The Ministry of Labor and Social Welfare should find ways to manage rightful foreign labor immigration with legality, tidiness and appropriate to each working situation in Thailand.

- The Ministry of Public Health can take the results of this investigation to apply and manage various epidemic diseases occurring in foreign immigrants illegally passing through Thailand without clinical examination.

- Provincial organizations or local government organizations can use the results of this investigation to allocate residence zones.

- The Ministry of the Interior can use the results of this investigation to lay down measurements of traffic safety and educate foreign immigrant laborers about traffic discipline and laws.

\subsection{Suggestions for Further Research}

- Research should be conducted about dimensions of cultural adaptation and an assimilation model of other foreign immigrant laborers in Thailand.

- A cultural adaptation model in ASEAN member countries should be investigated.

- Burmese community management in foreign immigrant labor residence areas should be studies.

- Environment effect resolution guidelines in industrial communities where foreign immigrant laborers have lived should be studied. 


\section{References}

Achawanichagul, K. (2002). Labor migration in Southeast Asia [in Thai]. Bangkok: Mahidol University.

Awanitchakul, K. et al. (1999). Labor transportation in Southeast Asia [in Thai]. Bangkok: Mahidol University

Chantavanit, S. (2001). International migration in the Asia-Pacific: Problems and policies [in Thai]. Bangkok: Chulalongkorn University Press.

Huget, J., \& Punpuing, S. (2005). International migration in Thailand [in Thai]. Bangkok: IOM.

Media, B. (2012). Thailand will become a leader of the AEC after 2015 [in Thai]. Industry, 54, 8-11.

Office of Foreign Worker Administration. (2011). Foreign immigrant labor information in 2011 [in Thai]. Bangkok: Department of Employment.

Santasombat, Y. (2005). Humanity and culture (3rd ed.) [in Thai]. Bangkok.

Sanyawiwat, S. (2007). Social Development Theories and Strategies [in Thai]. Bangkok: Office of Chulalongkorn University Printing.

Sibpapart, N. (2009). Human education security for foreigner immigrant children in Samut Sakhon province [in Thai]. Bangkok: Asian Research Center of Migration, Chulalongkorn University.

Tungmankhong, T. (2009). Burmese immigrant labor: Reconciliation living model in border area of Samut Sakhon Province [in Thai]. Mahasarakram: Mahasarakram University.

Wiwattanangan, P. (2012). Retrieved from http://humanrevod.wordpress.com/2012/01/30myanmar-workforce -effect

\section{Copyrights}

Copyright for this article is retained by the author(s), with first publication rights granted to the journal.

This is an open-access article distributed under the terms and conditions of the Creative Commons Attribution license (http://creativecommons.org/licenses/by/3.0/). 